\title{
Research and Practice of Developing Pattern for Engineering Leading Talents oriented to the need of Top Industry Talents
}

\author{
Ce Zhang*, Dianhui Chu, Jianan Jiang, Weigong Lv, Yiran Zhao
}

\author{
School of Computer Science and Technology, Harbin Institute of Technology at Weihai, 2 Cultural \\ West Road, 264209 Weihai, Shandong Province, China \\ zhangce@hitwh.edu.cn, chudianhui@vip.sina.com, susan_in@163.com, Iwgswl@sina.com, \\ 530634471@qq.com
}

\begin{abstract}
Keywords: Top industry talent, Engineering leading talent, Talent developing pattern, College-enterprise cooperating development.
\end{abstract}

\begin{abstract}
In recent years, domestic engineering education has yielded substantial results. Although droves of well-educated engineering talents are constantly emerging, the asset who has the top innovative engineering practice ability and engineering leading ability is still grossly inadequate. The obstacles that constraint the development for project leaders oriented to the need of top industry talents still haven't been exceeded. Accordingly, a developing pattern of project leaders oriented to the need of top industry talents is proposed. Aiming to strengthen students' practice ability, innovation ability and project leadership, a development framework of project leader oriented to the need of top industry talents is presented. Development resource system building, the students with the potential of project leader selecting and the top industry enterprises choosing are analyzed. In addition, college-enterprise associated faculty building, college-enterprise cooperating development and quality assurance mechanism in the process of development are dissected as well. The achieving process of developing the project leaders supported by both crossing associated development system and associated management mechanism is given. Essential problems that are urgently to be solved are analyzed. Ultimately, it is concluded that development of project leaders oriented to the need of top industry talents is not only an important caution to develop students with leadership in domestic engineering education of college, but also a major field to construct specialization innovation education system directed by talents development.
\end{abstract}

\section{Introduction}

Purely emphasizing the ability to solve problems with technology is one of the disadvantages of current engineering education, while the leading role of the project leader in a project team has been ignored[1], which causes that the shortage of leaders has been haunting the promotion of top industry with project development as the important feature. As a result, advancing leadership is a practical matter to be urgently solved.

The essential of industry competition concentrates on various aspects, but primarily it's the competition among high-level talents. Currently, the requirement for technology and innovation is stronger than ever, and the need of top leader is more urgent than ever as well.

The principle that engineering education should follow is that the development of project leaders should take a learning method based on the combination of course and engineering project. The education method directed by the aim to develop talents with innovation of both engineering and project should be tried to be built. The combination of college and enterprise is the education theory to be positively implemented. The specific innovative talent development pattern based on engineering project has to be explored and pushed. Students' engineering innovation, practice 
ability and project leadership will be completely developed.

The project leadership development plan offers a practice platform and chance for some excellent students with leading potential to improve their project leadership, which lays a solid foundation to make them to be high-level comprehensive talents with project leadership.

Through the internship in the enterprise and the interaction with the leaders of the enterprise, students will unconsciously feel and study their sharp intuitivism, experienced social skill and excellent organization and management ability, which play an important role in enterprise's managing and running. Students will deeply grasp expertise by participating the plan and implementation of project and become excellent engineer. The leadership course combines the theory study, enterprise management practice and real engineering project, which more easily makes student to be a project leader with technology innovation, leadership and management ability.

\section{Domestic and Foreign Situation}

MIT, where "Practical Education" keeps ahead in the USA, carries out Gordon Project Leadership Plan, which is the source of the proposed project leadership development. [3] [4] [5] [6] [7] Gordon Project Leadership Plan was presented in 2007, and it's a reformation project for engineering undergraduates teaching. [4] [6] The aim is to improve MIT project and technology education level and develop project leaders (project leadership) of 21 century. The core of Gordon plan is to select excellent students among all the junior students of engineering school. Through specific leadership study, discussion and practice in class, especially enterprise practice, students will developed to be the leaders of engineering, innovation and practice in the future.

Driving by the engineering leadership program of MIT, some famous universities in the USA start various talent development plan based on engineering leadership development. [8] [9] [10] [11] For example, the Engineering Leadership Development Program (ELDP) of Pennsylvania State University improves students' leadership by course discussion, society practice, situation study, even studying abroad and other ways; the Engineering Leadership Program (ELP) of Lowa State University focuses on how the engineers can better service for the society, and it's implemented and managed by students; the Global Engineering Program and Engineering Projects In Community Service (EPICS) of Purdue University, and the primary content of EPICS is the engineering projects in the communities; Turtle Camp (TC) of University of Maryland; Global Engineering Leadership Program of the University of Michigan; Engineering Leadership Program of Lowa State University; Stanford Technology Adventure Program of Stanford University; Engineering Leadership Program of the University of Colorado and etc. Generally, engineering leadership can be summarized as following three features, [12] including leadership attitude, leadership behavior and leadership technique.

China follows the engineering leadership development reformation of the USA and positively takes measures. The reformation of foreign countries has been observed seriously [13] [14] [15]. After careful deliberation considering domestic features [16] [17], primary research has been done in the pattern [18], factors [19], specific scheme [12] [20] and optimization operation [21] of engineering leadership development, and there has been progress.

At present, China and French built a cooperation system, and China-French Engineering School was built in Beijing University of Aeronautics and Astronautics. Based on the engineering education experience of both sides, development system of future engineering leadership and entrepreneur was discussed. North Western Polytechnical University issued “5438” pattern (5 
combination, 4 focus, 3 platform and 8 measures) to develop high-quality innovation astronautics leadership. Tsinghua University carried out leadership training. Business School of Renmin University of China made effective leadership development program. These projects and programs make positive contributions to domestic leadership education exploration and bear fruit. But comparatively, engineering leadership education of domestic colleges is in the initial stage, and there are few relevant universities. The systematic and formalized engineering leadership development system hasn’t been explored.

Engineering leadership development targets for top innovation engineering technology leadership, which is an important move of engineering undergraduate education reformation. In order to strengthen students' practice ability, innovation and engineering leadership, it plays an important role in developing high-quality and comprehensive talents, improving industry to a higher level and promoting domestic manufacturing industry to intelligent manufacturing. Engineering leadership development is a positive exploration in the process of education information.

\section{Engineering Leading Personnel Development Framework oriented to the need of Top Industry Talents}

\section{(1) Research Contents}

The guiding ideology of this program is to build a world first-class university, strengthen morality and qualification, develop basic natural science and improve students’ practice ability.

The research and practice of engineering leadership development pattern oriented to the need of top industry talents are closely bound up the quality that engineering leadership need, including leadership knowledge, engineering leadership talent, engineering thoughts, leadership attitude and individual quality. The program means to strengthen students' practice ability, innovation and engineering leadership. Through the specialized training for top students with leadership potential, college-enterprise cooperation, joint training and double tutorial system, this program provides a practice platform and chance for students, whose innovation and engineering leadership will be improved. The program will lay firm foundations for high-level compound talents with engineering leadership. The engineering leadership development framework oriented to the need of top industry talents is given in Fig.1.

Directed by engineering leadership, it can be seen that engineering leadership program aims to develop engineering leadership talents. Through a series of growth environment system for supporting innovation engineering talents, including course, developing resources, faculty, teaching management, assessment and assurance, the program combines professional education and leadership education, course study and project study, campus education and enterprise education, common education and individual education, and objective management and process management. Top innovation engineering leading personnel will be developed with practice ability, innovation and engineering leadership. 


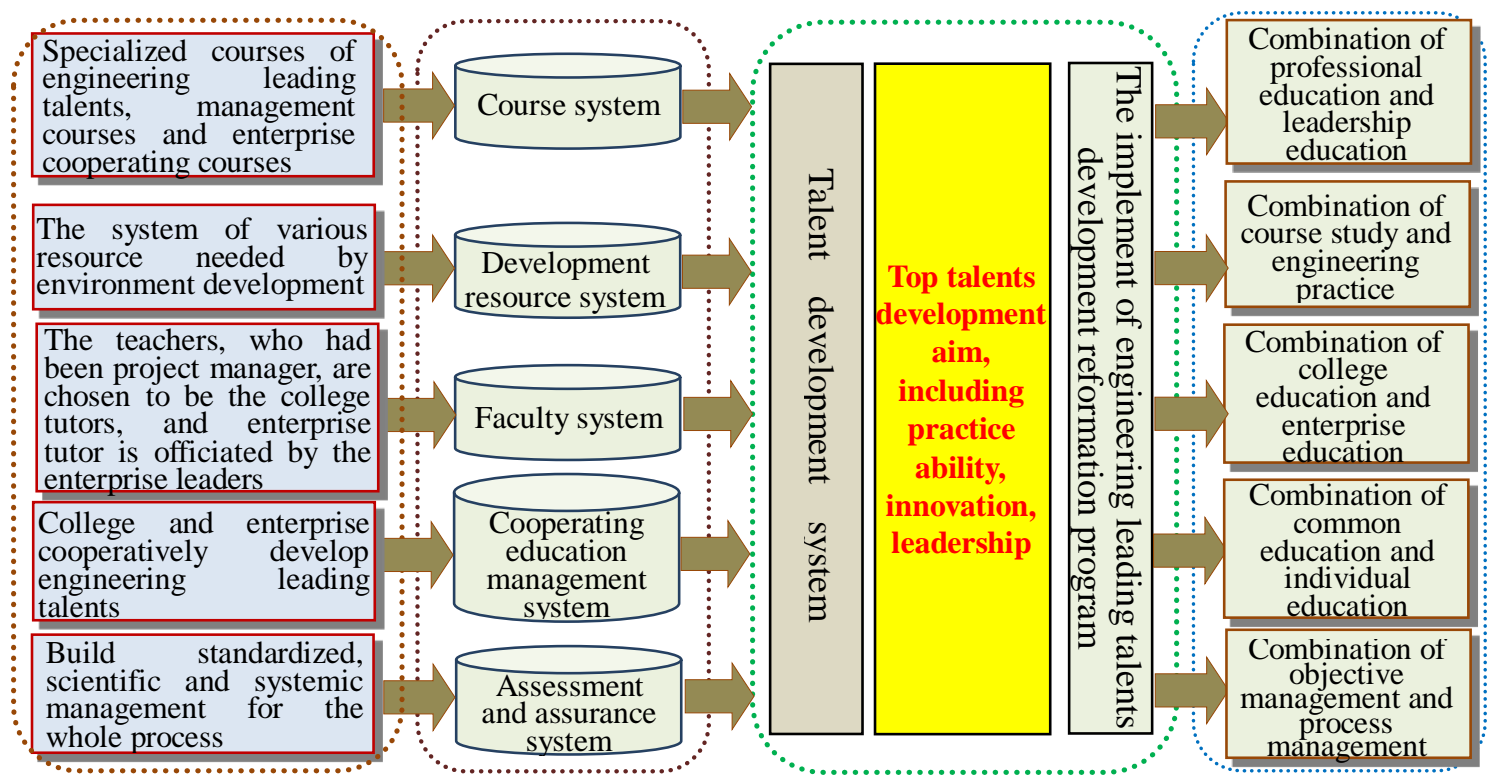

Fig.1. Engineering leading personnel development framework oriented to the need of top industry talents

The research and implementing contents of engineering leading personnel development pattern consist of following five respects.

1) Development resource system construction based on development process of engineering leading personnel

The essential of this program is to cooperate with famous enterprises more deeply and implement high-level development program for engineering leading personnel. A number of excellent students with leading potential will be selected to have leadership internship in enterprise every year to improve international engineering leadership of excellent students. On the basis of the main process of engineering leading personnel development, resource system need to be built to satisfy development environment, including course arrangement of college education, theory teaching, practice training, faculty, engineering practice project, leadership training, famous enterprise, real engineering scene of enterprise education and enterprise tutors.

Various types of tutors and development process are involved in engineering leading personnel program. The program is obviously characteristic of multiple perspectives and processes, where there is a specific system. Fig.2 shows the construction thought of crossing cooperation education system participated by sorts of characters with multiple perspectives and processes in our comprehension.

The selected students have to finish the courses taught by lecturers at college. Based on the reality that the shortage of leadership theory, engineering leadership courses are taught by professional management teachers. (Temporarily four courses) After that, students will take leadership training to develop primary leadership. Meanwhile, to improve students' ability to research and development of engineering projects, school research laboratory offers research condition for research projects. In the enterprises, students participate engineering projects of enterprises for development practice, directly guided by project manager and assisted by teachers of college. Through project development and interaction with enterprise tutors, students will improve engineering innovation and leadership. If it is necessary, tutors of college can participate the instruction. When it comes to graduation design, instructed by college and enterprise, students have to finish a graduation design originated from real project of enterprise. 
In brief, the crossing cooperating education system consists of multiple respects, including course, faculty, practice, management and assurance system. A comprehensive development resource system is constructed with the above respects. Therefore, engineering leading personnel program can be concluded as follows: college and enterprise together participate in providing a condition for students to innovate in engineering and improve leadership, build education system and construct a new pattern for colleges to develop talents with enterprises.

2) Selection of students with engineering leadership potential and top industry enterprises

Engineering leading personnel development is a college-enterprise joint education system. Engineering leader personnel is developed for top innovation by both college and enterprise. As a consequence, excellent students with engineering leadership potential have to be selected. At the same time, top industry enterprises also have to be selected. The selected students, who has solid professional knowledge, technique and primary engineering leadership, will be trained for better engineering leadership.

The selection range, principle and procedure have to be established. It has to make sure that the selected students have the basic abilities that this program needs. On the basis of the existing industry internship base, resources have to be expanded further. A batch of qualified external internship base will be newly built. Double tutorial system is implemented in this program. Outstanding students will be chosen to practice in the enterprise. Students' leadership will be improved and enterprise experiences will be more abundant. Based on the cooperative laboratory built with domestic famous enterprise, college-enterprise cooperation and industry education will be strengthened further.

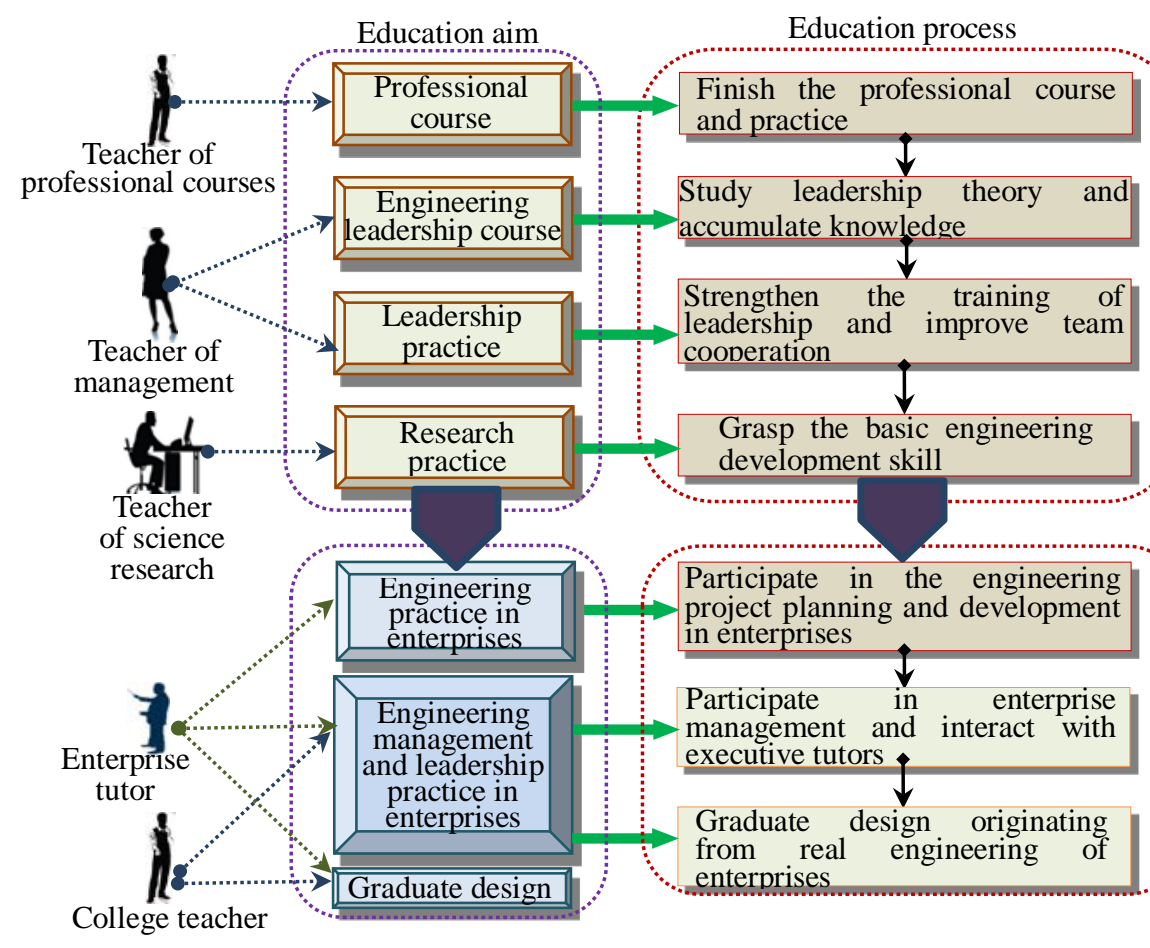

Fig.2. Crossing cooperating education system participated by sorts of characters

3) College-enterprise cooperation faculty build

According to the internal requirement, the involved teachers should have high-level engineering development leadership experience. Based on the realities of the subjects and teachers, combined with multiple channels, the teachers with the experiences as project leader will be top 
priority to be arranged to teach courses. In addition, project managers, department managers and enterprise managers will be invited to teach in the college. After leadership practice training, a new faculty team with abundant leadership development teaching experience will be built. To make sure that students will obey the methods taught by teachers after they enter enterprise, enterprise tutors, who are experienced in engineering planning, development ability and enterprise management, are invited from cooperated enterprises. Students will take part in real engineering build and the process of engineering and enterprise management, and enterprise education plays a unique role.

4) College-enterprise cooperative education and individual and flexible management system

Based on the previous achievements, the development condition should be emphasized to be construct to adapt to excellent students with engineering leadership potential. Meanwhile, college-enterprise cooperating education and combination of course and engineering practice need to be studied.

(1)College-enterprise cooperating education

Based on various system cooperating with famous IT enterprises, students with outstanding engineering leadership potential are selected to enter enterprises. Engineering education and leadership promotion are implemented to train engineering leading personnel in technology innovation and management ability. Accordingly, the cooperating education system should comprehensively take development of both college and enterprise into account. Enterprises' basic requirements for selected students need to be considered at college, while special requirements for developing talents need to be considered in enterprises. College education focuses on the theory study of engineering leadership and team training, while enterprise education focuses on project planning, implementing and practice. Both college education and enterprise education are applied and combined in the program.

(2) Combining training of class study and engineering practice

The excellent students with engineering leadership potential will get targeting instruction in the program. Individual development combining engineering management study and engineering leadership is implemented. Class study is based on engineering leadership and engineering project management training, while engineering practice is based on project planning and development. By coordinating class study and engineering practice, students will be trained in individual study, problem solving, engineering practice, project management, team coordination capacity and comprehensive innovation.

5) Quality assurance system for training process

Engineering leading personnel development program is participated by both college and enterprise, including theory course at college, training class, and enterprise internship practice. The program is a talent development reformation aiming to improve excellent students' engineering innovation and leadership. The whole procedure is regarded as the master line of the program. Specific arrangement and requirement are make for all the segments of the program, such as student selection, engineering leadership course, engineering training, entering training, project developing, engineering management and graduate design. Directed by the objective, the procedural management is implemented, and the development quality can be guaranteed.

\section{(2) Research aim}

Combining computer science major and subject feature, this education reformation research deeply studies the development pattern of engineering leading personnel oriented to top industry. By the joint training with domestic famous computer enterprises, the individual development and flexible management under the combination of college and enterprise are implemented. The 
crossing cooperating education and management system participated by multiple sides needs to be explored.

1) Implement engineering leading personnel development program. Through the college-enterprise cooperating development, the excellent students with leadership potential are specially trained and developed to improve their innovation and engineering leadership. The college-enterprise cooperation provide practice platform and chance for the students, and lays firm foundation for them to be high-level compound talents with engineering leadership. The students will be trained in strong professional skills, good comprehensive qualities, abstract thinking, logic thinking and systematic perspective. They will be high leading personnel with innovation spirit and practice ability.

2) The engineering leading personnel development program deepens and emphases on college-enterprise cooperation. The program also creates well-educated, cooperating-educated and individual-educated condition and environment to train top engineering innovation talents. Internationally competitive engineering leading personnel will be built to service for new industrialization development and economic sustainable society development in future China.

Fig. 3 shows the achieving process of engineering leading personnel development aim.

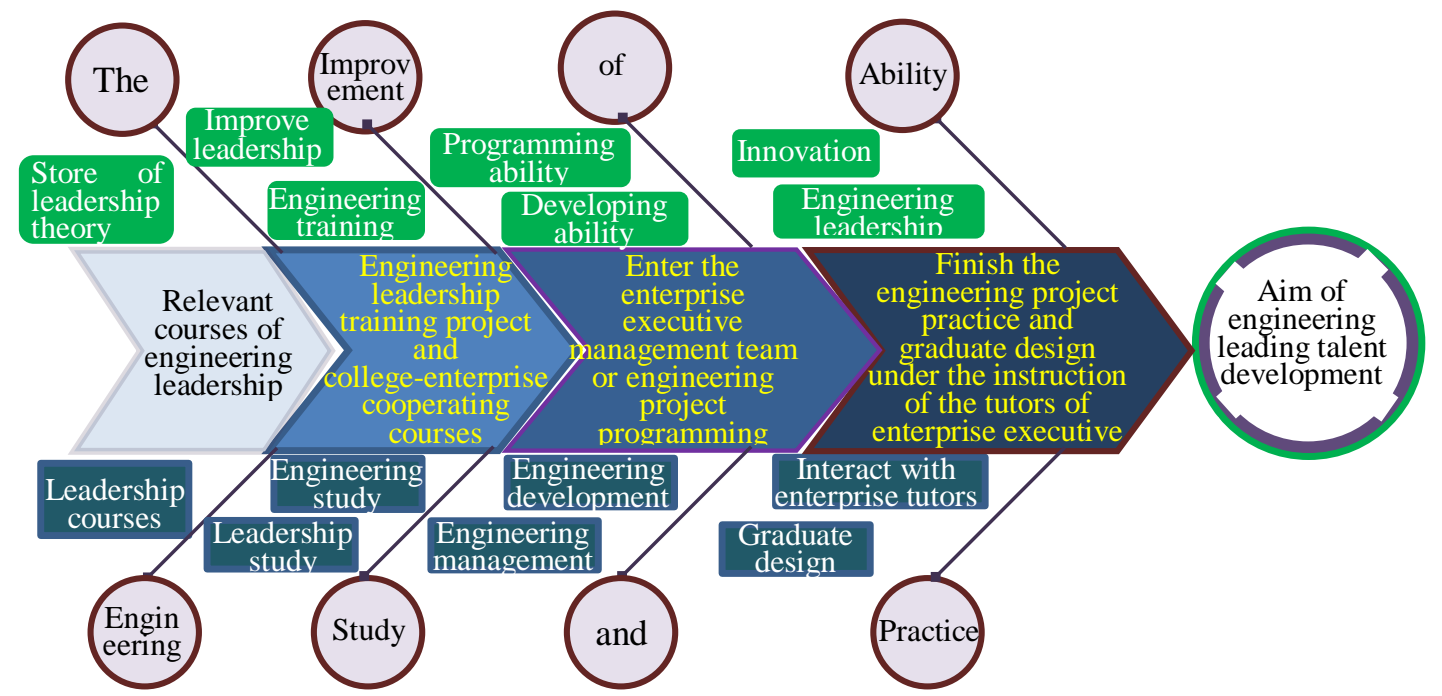

Fig.3 Achieving process of engineering leading personnel development aim figure.

Engineering leading personnel come from the leadership theory study in college and engineering training. Subsequently, they have the chance to enter the enterprise to do engineering development and enterprise management practice. Talents development goal will be reached through college-enterprise cooperating development and cooperating education system.

\section{(3) Intended key problems}

The important task for the development of engineering leading talents oriented to the top industry talents is to train internationally competitive engineering leading talents with high quality. Based on the reality of college engineering education, individual feature of engineering college and accumulated experience of engineering talent development, the following problems need to be solved in the development program directed by engineering leadership:

1) Gather resources and build development environment adapting to the effective growth of engineering leading talents

Developing engineering leading talents is the important aim of top engineering talents education. It must be supported by fitting systemic and great education resource. Great education resource should be provided to train engineering leading talents with top innovation. Building from 
student resource, faculty, course and environment, the development environment for first-class engineering leading talents will be better.

High-quality students come from great students of low proportion. High-quality faculty come from the tutors with strong professional competencies and leaders of famous enterprises. High-quality courses cover specific engineering leadership courses. High-quality environment is provided by famous computer companies.

2) Crossing cooperating education system based on college-enterprise cooperating development.

The students with engineering leadership potential are instructed exclusively and individually trained from courses of college and engineering of enterprise. Class study and engineering practice need to combine, and engineering innovation thought and engineering leadership need to be strengthened. College education and enterprise internship education should combine, and theory study, enterprise development and management quality need to be trained.

3) Deepen the development pattern for engineering leading talents

A new development pattern, combining college and enterprises, for engineering leading talents needs to be further explored. It is a comprehensive pattern consisting of knowledge study, including leadership courses, and engineering leadership. The construction from course study to engineering development has to be optimized. The system obstacles preventing the promotion of engineering leadership in college education need to be broken. College education, especially engineering education, has to be connected to the engineering leading talent development needed by the enterprises. The last one kilometer has to be breakthrough in the development for engineering leading talents.

Based on the above first and second problem, disadvantages need to be found from student selection, leadership course, engineering practice and leadership build. The education way, combining the individual development and flexible management, has to be strengthened. "College students-enterprise leading talents" thorough system should be built. The gap between college education and the top industry's need of engineering leading talents will be narrowed.

\section{Conclusion}

The development for engineering leading talents oriented to the need of top industry is more objective in the position of talent development and has more specific aim. It is a new try and reformation of engineering education in college. Through the college-enterprise cooperating development, students with leadership potential will be given engineering leadership education and enterprise engineering practice. The students will be trained in the innovation and leadership in engineering development. Meanwhile, based on the interaction with enterprise tutors, student can feel and take part in part of the management of enterprise and participate in the planning and implementing of engineering project, which will help broaden the horizon of the industry and develop sense of responsibility.

The development for engineering leading talents oriented to the need of top industry is an important caution for the college engineering education to develop engineering leading talents, and an essential respect of specialized innovation education system directed by talent development. It plays a significant role in implementing the education and study pattern called "Regard students as the center”. It also provides talent assurance for new industrialization development and sustainable development of economic society in future China. 


\section{Acknowledgement}

In this paper, the research was sponsored by the 2016 Undergraduate College Education Reform Research of Shandong Province, "Research and practice of development pattern for engineering leading talents oriented to the need of top industry talents” (B2016M016). The research was also sponsored by the 2017 industry-education cooperating education project, "Constructing laboratories of Internet of things directed by solving the ability development with complex engineering problems”. The research was sponsored by the 2016 postgraduate education innovation program, "Research on the multiple dimension education quality assessment system oriented to the special master" (SDYZ1603) and a research project of Harbin Institute of Technology at Weihai, "Research and practice on the development pattern for full stack talents of Internet of things" (BK201602).

\section{References}

[1] Gary Lee Downey, Juan C. Lucena. Globalization, Diversity, Leadership, and Problem Definition in Engineering Education [J]. 1st International Conference on Research in Engineering Education. Honolulu, June, 2007: 5.

[2] http://news.hexun.com/2012-08-18/144894352.html

[3] Jun Cui, Xia Wang. Engineering leading talents development: Engineering leadership education of MIT [J]. Higher Education of Science, 2010(6): 30-35.

[4] Huan Lei, Crawley Edward. Engineering leadership guiding the development of the world Summary of Gordon Engineering Leadership Program of MIT [J]. Tsinghua University Education Research, 2010, 31(1): 77-83.

[5] Ruth Graham, Edward Crawley, Bruce R. Mendelsohn, Engineering leadership education: A snapshot review of international good practice, White Paper sponsored by the Bernard $\mathrm{M}$. Gordon - MIT Engineering Leadership Program, 2009

[6] Capabilities of Effective Engineering Leaders, Version 3.4, Bernard M. Gordon-MIT Engineering Leadership Program, September http://web.mit.edu/gordonelp/leadershipcapabilities.pdf

[7] Qing Lei, Xiang Gong. Analysis of the feature of the engineering leading talents development program — taking Gordon-MIT Engineering Leadership Program as example[J]. Journal of Beijing University of Aeronautics and Astronautics (Social Sciences), 2010, 23(1): 108-113.

[8] Kalkhoff M, Athreya K S, Rover D, et al. Work in progress-highlights and challenges of a student driven co-curricular leadership program//Frontiers in Education Conference, 2009. FIE09, 39th IEEE. IEEE, 2009: 1 2.

[9] Schuhmann R J. Engineering leadership education: the search for definition and a curricular approach[J]. Journal of Stem Education, 2010(11): 61-69.

[10] Athreya K S, Kalkhoff M, McGrath G, et al. Engineering Leadership Program: Tracking Leadership Development of Students using Personalized Portfolios//38th ASEE/IEEE Frontiers in Education Conference, 2008.

[11]Wenxia Cui, Dan Zhang. A Study on the Student Leadership Program in the University of Maryland [J]. World Education Information, 2013(11): 18-23.

[12]Jing Zhou, Aihuang Guo. Cultivation of Engineering Leadership in Higher Education [J]. Computer Education, 2013(5): 106-110.

[13]Lingzhao Kong, Jian Lin. American College Students' Leadership Education under the Concept of "Leadership" in Post - Industrial Age[J]. Tsinghua University Education Research, 2013, 
34(5): 81-87.

[14]Qi Liu. From First-class Scientists to Excellence Leaders - Reflections on Compton, Massachusetts Institute of Technology Compton [J]. Higher Education Management, 2014, 8(2): 17-22.

[15]Guoming Liang. A Comparative Study of the US and Russia in the Training Model of Engineering Leadership [D]. Harbin Institute of Technology, 2013.

[16]Jian Lin, Zhidan Xu. International Engineering Leadership Education and Its Enlightenment to China ( I ) [J]. Research on Higher Engineering Education, 2014(3): 7-17.

[17]Dong Li, Shengjun Yin. Paying Attention to Engineering Leadership and Cultivating IT Engineering Talents [J]. Computer Education, 2015(15): 2-5.

[18]Zhigang Hu, Shengbing Ren, Zhigang Chen. Undergraduate Talents Training Program and Its Optimization - Based on the Idea of CDIO - CMM [J]. Research on Higher Engineering Education, 2010(6): 20-28.

[19] Weiwei Ye, Min Ye. Research on the Elements of Engineering Leadership [J]. Research on Higher Engineering Education, 2011(5): 92-95.

[20] Mingchan Cheng. Research on the Innovation Mode of Engineering Leadership Development [D]. Zhejiang University, 2011

[21]Jian Lin. Excellent engineer leadership training [J]. Research on Higher Engineering Education, 2012(4): 1-14.

[22]Duolei Zhang. China - French cooperation in training engineering leader [J]. International Talent Exchange, 2010(5): 62-62.

[23] http://www.huaue.com/unews2014/2016111283127.htm

[24]Zhiqing Li. Cultivation of College Students' Engineering Leadership [J]. Continuing education research, 2013(8): 122-124. 